\title{
Fetomaternal outcomes of hospitalized hypertensive gravida in Shaqra General Hospital: a retrospective study
}

\author{
Russel S. Abalos ${ }^{1 *}$, Rosanta O. Ellasus ${ }^{1}$, John Mark M. Gutierrez ${ }^{2}$ \\ ${ }^{1}$ Department of Nursing, College of Applied Medical Sciences, Shaqra Female Campus, Shaqra University, Kingdom of Saudi Arabia \\ ${ }^{2}$ Department of Nursing, College of Applied Medical Sciences, Shaqra Male Campus, Shaqra University, Kingdom of Saudi Arabia \\ *Corresponding author E-mail: ruz.tik24@yahoo.com
}

\begin{abstract}
Background: Elevation of blood pressure during pregnancy can adversely affect both fetal and maternal outcomes. Other maternal and fetal complications may also arise which may result to maternal and fetal mortality.

Objective: This study aimed to determine the fetal and maternal outcomes of hospitalized pregnant clients with hypertension.

Methods: This 6-year retrospective research design was carried out in Shaqra General Hospital between January 2008 and November 2013. Following approval by the hospital research ethics committee and hospital administrators, hospital records were reviewed and examined using guide checklist. Universal sampling was applied totaling to 56 evaluable cases of pregnant women with hypertension.

Results: Of 56 cases studied, year 2008 to 2013 had the most frequency of hypertensive mothers. Most women are in middle adulthood stage with age 25 years old and above, had more than one pregnancy (multigravida) and more than one viable pregnancy (multipara). Fetal outcome resulted to high number of babies who were term, appropriate for gestational age, with good Apgar score, no birth defect but high frequency of neonatal intensive care unit (NICU) admissions. Maternal outcome recorded no maternal deaths; however, 4\% maternal complications (i.e., post-partum hemorrhage and HELLP syndrome) and more caesarean section deliveries were observed.

Conclusion: Good Apgar score and absence of birth defects is associated with higher frequency of roomed-in babies and less NICU admissions. There were lesser complications to mothers who had more than one pregnancy. There were more NICU admissions from caesarean section deliveries.
\end{abstract}

Keywords: Fetal Outcome, Hospitalized Hypertensive Gravida, Hypertensive Disorders of Pregnancy, Maternal Outcome and Retrospective Study.

\section{Introduction}

According to the 2000 global report on maternal mortality, the World Health Organization (WHO), the United Nations Children's Fund (UNICEF) and the United Nations Population Fund (UNFPA) estimate that 529,000 women worldwide die annually due to pregnancy and childbirth complications. Such cases of maternal mortality can be attributed to hypertensive disorders of pregnancy (HDP) and other maternal conditions.

HDP, including chronic hypertension, gestational hypertension, pre-eclampsia and eclampsia (Leeman \& Fontaine 2008), represent a group of conditions associated with high blood pressure during pregnancy, proteinuria and in some cases convulsions (Dolea \& AbouZahr 2003). Furthermore, these conditions remain one of the largest single causes of maternal and fetal morbidity and mortality, accounting for $16.1 \%$ of maternal deaths in developed countries (Patel et al. 2013). In 2012, Saudi Arabia has estimated a crude death rate of 300 per 100,000 populations (The World Bank 2014). Among of the top leading mortality, low birth weight, congenital anomalies, and maternal conditions ranked number eight (3,882 death), ninth (2,545 deaths), forty-seventh (142 deaths) in the latest estimated deaths in Saudi Arabia, respectively (LeDuc Media 2014). Also, the country's recorded infant mortality rate was 13 per 1,000 live births, while the estimated maternal mortality ratio was 16 per 100,000 live births (The World Bank 2014).
In their recent study, Naeem, Naeem and Hanif (2014) explored and compared the pregnancy outcomes of hypertensive and normotensive Pakistani population. Based on their findings, maternal age and history of pregnancy was found to be significantly associated with hypertensive disorders of pregnancy. The risk of adverse pregnancy outcome is higher among hypertensive pregnant women compared to pregnant women with normal blood pressure. Similarly, Olusanya \& Solanke (2012) have determined adverse perinatal outcomes of HDP. Their finding suggests that surviving newborns of mothers with HDP in low-income countries are at risk in developing neuro-developmental deficits. In their current exploratory descriptive study, Hafez, Dorgham and Sayed (2014) have used the Morrison and Olsen High-Risk Scoring Tool to identify the profile of high-risk pregnancy among Saudi pregnant women in Taif. Their results revealed $44 \%$ of Saudi women with high-risk pregnancy aged between 30-35 years old. Majority of them had 5 to 12 previous pregnancies. The maternal conditions have resulted to pregnancy complications $(66 \%)$ with different medical associated conditions during their current pregnancies, such as, anemia $(25.3 \%)$, gestational diabetes $(16.2 \%)$, pregnancy induced hypertension (15.2\%).

Although various database have illustrated the number of morbidity and mortality associated with low birth weight, congenital anomalies and maternal conditions worldwide, there still few evidence concerning the relationship between HDP and fetal and maternal outcomes in Saudi Arabia. The resulting insufficient 
evidence motivated this study to explore and describe the fetomaternal outcomes of hypertensive mothers admitted in Shaqra General Hospital (SGH). In addition, this current study wanted to address significant problems toward improving maternal health and prevents pregnancy-related complications.

\subsection{Objectives}

In general, this study aimed to determine the fetal and maternal outcome of pregnant women with hypertension admitted in SGH from 6-year period of 2008 to 2013. Specifically, it sought to find the following objectives:

- To determine frequency distribution of hypertensive pregnant patients in 6-year period, from 2008 to 2013 ;

- To determine profile of the pregnant women with hypertension according to (a) age, (b) gravidity and (c) parity;

- To determine fetal outcome according to (a) gestational age, (b) fetal weight, (c) APGAR score, (d) birth defect and (e) fetal disposition;

- To determine the maternal outcome in terms of (a) method of delivery, (b) maternal complication and (c) maternal mortality; and

- To determine relationship between patients' profile and fetal outcome, within and among fetal outcomes, between patients' profile and maternal outcome and between fetal outcome and maternal outcome.

\section{Methods}

\subsection{Design and procedures}

This study utilized retrospective research design. Collection of data began after seeking for approval to conduct the study from the concerned authorities of the hospital administration. The main tool for the data gathering was a guide checklist, which contained information about patient's demographic profile, fetal outcome and maternal outcome. To ensure validity, items in the checklist guide were subjected to content analysis and pre-testing. A sample of five (5) files excluded from the study was reviewed and examined to identify the flaws of the instrument. When corrections had been integrated, the final checklist guide was prepared and used. All the information was taken through record analysis where patients' files were accessed in the medical record section of the hospital. Data were tallied, tabulated and computed utilizing the different tools for data analysis to come up with valid results.

\subsection{Study population and setting}

This study was conducted in SGH located in Shaqra City, Riyadh, Saudi Arabia. SGH is a government hospital supervised by the Ministry of Health. It is the only healthcare facility that caters health care services in Shaqra City; thus, it is an ideal setting to determine fetal and maternal outcomes.

Moreover, the participants of the study included the whole population of patients admitted between 2008 and 2013, hence, the universal sampling was applied totaling to 56 cases. Cases were chosen based on the following inclusion criteria: (1) pregnant women with any of the types of hypertension (i.e., gestational hypertension, pre-eclampsia, eclampia), (2) without any other chronic diseases or concurrent disorders, and who delivered to a singleton baby. Patients with co-existing medical problems (i.e., hypothyroidism, diabetes mellitus) and patients with multi-fetal pregnancy (i.e., twins) were excluded.

\subsection{Data analysis}

Results were presented as frequencies and percentages to determine the patients' profiles, fetal outcome and maternal outcome. To determine any relationships between and among the variables, the Pearson's Product Moment Correlation was applied using statistical significance at $p<0.05$. All the data were processed using the Microsoft ${ }^{\circledR}$ Excel program and Statistical Package for the Social Sciences (SPSS) Version 15.0.

\subsection{Ethical consideration}

Researchers had requested permission from the hospital authorities to carry out the research. Hospital protocols and research ethics in pursuing the study were ensured. The consent for research on medical records was waived because all data taken from the files were considered highly confidential and no part of this study was produced that may divulge the identities of the patients or their families or significant others. Furthermore, no health or physical injuries were incurred because no direct contact with any participants was involved.

\section{Results}

\subsection{Frequency distribution of hospitalized hypertensive gravida in SGH from year 2008 to 2013}

This 6-year retrospective study covered year 2008 to 2013 with the distribution of hypertensive pregnant patients who were hospitalized and delivered during this period as shown in Table 1 . The highest frequency number was noted during the years 2009 and 2012 with 12 cases $(21.4 \%)$ each. Years 2010 and 2011 had 11 cases (19.6\%) each; while 2013 and 2008 hit the low cases of 6 $(10.7 \%)$ and $4(7.1 \%)$, respectively.

Table 1: Frequency Distribution of Hospitalized Hypertensive Gravida $(\mathrm{N}=56)$

\begin{tabular}{ll}
\hline Year & Frequency of Cases $(\%)$ \\
\hline 2008 & $4(7.1)$ \\
2009 & $12(21.4)$ \\
2010 & $11(19.6)$ \\
2011 & $11(19.6)$ \\
2012 & $12(21.4)$ \\
2013 & $6(10.7)$ \\
Total & $56(100)$ \\
\hline
\end{tabular}

\subsection{Patients' profile}

\subsubsection{Age}

The ages of the patients noticeably fell on the above 25 years old category with $49(87.5 \%)$ cases (the oldest recorded age was 42 years old) and only few were in the 20 to 24 years old age range with $7(12.5 \%)$ cases only.

\subsubsection{Gravidity}

'Gravidity' refers to the number of pregnancy of the patients. More than two-thirds (71.4\%) of the population were multigravida with number of pregnancies ranging from frequency of 2 to 13 . Only 16 cases $(28.6 \%)$ were primigravida or in their first pregnancy.

\subsubsection{Parity}

'Parity', which means the number of pregnancy that had fetus reached the age of viability (at least 20 weeks of gestation), was also illustrated. Likewise, the highest number of cases was 38; corresponding to $67.9 \%$ of the total population. These cases were multiparity with parity of 2 to 12 . A smaller number of 18 patients $(32.1 \%)$ were cases of first parity. A detailed description of patients' profile distribution is illustrated in Table 2: 
Table 2: Patients' Profile Distribution $(\mathrm{N}=56)$

\begin{tabular}{ll}
\hline Demographic Characteristics & Frequency of Cases $(\%)$ \\
\hline Age (years) & $56(100)$ \\
$20-24$ & $7(12.5)$ \\
${\text { above } 25^{*}}^{*}$ & $49(87.5)$ \\
Gravidity $^{\text {Primigravida }}{ }^{\mathrm{a}}$ & $56(100)$ \\
Multigravida $^{\mathrm{b}}$ & $16(28.6)$ \\
Parity $^{\text {Primiparity }}{ }^{\mathrm{c}}$ & $40(71.4)$ \\
Multiparity $^{\mathrm{d}}$ & $56(100)$ \\
\hline
\end{tabular}

${ }^{\mathrm{a}}$ First pregnancy

${ }^{\mathrm{b}}$ Second pregnancy or more

${ }^{\mathrm{c}}$ First pregnancy that reached age of viability

${ }^{\mathrm{d}}$ Second pregnancy or more that reached age of viability

* Oldest recorded age was 42 years old.

\subsection{Fetal outcome}

\subsubsection{Gestational age}

Despite the presence of hypertension among pregnant mothers delivered babies were mostly full terms with 37 cases (66\%). This means that pregnant mothers had reached the ideal age of gestation of 37 to 42 weeks. Some fetuses were categorized as preterm with 15 recorded cases $(27 \%)$, indicating that they were born before they reach 37 weeks. Post-term babies constitute the leas number of cases with only 4 reported cases $(7 \%)$ were delivered after 42 weeks.

\subsubsection{Fetal weight}

Weight of the fetus upon delivery was measured to see if the fetuses' weight is suitable for his or her gestational age. Based on existing medical records, the study found that more than one-half of the babies with 33 cases (59\%) were appropriate for their gestational age (AGA), which means that their weights were suitable in relation to their age. However, the combined numbers of small and large babies were also nearly high where 13 babies (23\%) were large for their gestational age (LGA) and 10 cases (18\%) were small for their gestational age (SGA).

\subsubsection{APGAR Score}

APGAR score (test performed on babies at 1 and 5 minutes after birth) after the five minutes of life was determined and tallied to see if the baby can successfully adapt to his or her environment. Most babies had good APGAR score with frequency of 37 (66\%) recorded cases. There were fewer cases recorded with fair APGAR score with 17 cases (30\%) and at least 2 babies (4\%) had poor APGAR score including one case of intrauterine fetal death (IUFD).

\subsubsection{Birth defects}

The records were examined to distinguish if the babies had any birth defects or congenital anomalies. The result revealed that 55 babies or around $98 \%$ had no defects. The case of IUFD was not further examined because no test measures were done to determine birth defects or congenital anomalies.

\subsubsection{Fetal disposition}

The findings show that babies born to hypertensive mothers were mostly in need of further assessment and medical intervention. Seventy percent of the recorded cases $(n=40)$ were delivered and admitted to the neonatal intensive care unit (NICU). There were 15 reported cases $(27 \%)$ that were considered well babies who did not need any medical management; hence, they were roomed-in with their mothers. Only $2 \%$ of fetal mortality ( 1 case) was recorded. The following table shows the detailed descriptions of fetal outcome:
Table 3: Fetal Outcome ( $\mathrm{N}=56)$

\begin{tabular}{ll}
\hline Demographic Characteristics & Frequency of Cases $(\%)$ \\
\hline Gestational status $^{\text {Preterm birth }}{ }^{\mathrm{a}}$ & $56(100)$ \\
Term birth $^{\mathrm{b}}$ & $15(27)$ \\
Post-term birth $^{\mathrm{c}}$ & $37(66)$ \\
Fetal weight $_{\text {SGA }}$ & $4(7)$ \\
AGA & $56(100)$ \\
LGA & $13(23)$ \\
APGAR score & $33(59)$ \\
Good & $10(18)$ \\
Fair & $56(100)$ \\
Poor & $37(66)$ \\
Birth defect & $17(30)$ \\
No birth defects & $2 *(4)$ \\
With defect or congenital anomaly & $56(100)$ \\
Mortality & $55(98)$ \\
Fetal disposition & $0(0)$ \\
Roomed-in & $1(2)$ \\
Admitted & \\
Mortality* & $56(100)$ \\
\hline
\end{tabular}

${ }^{\mathrm{a}}$ Born less than 37 weeks of gestational age.

${ }^{\mathrm{b}}$ Born at 37 to 42 weeks of gestational age.

${ }^{\mathrm{c}}$ Born after 42 weeks of gestational age.

${ }^{\mathrm{d}}$ neonatal intensive care unit.

SGA, small for gestational age.

AGA, appropriate for gestational age.

LGA, large for gestational age.

APGAR, test performed on babies at 1 and 5 minutes after birth

*Intrauterine fetal death or stillbirth

\subsection{Maternal outcome}

\subsubsection{Method of delivery}

The hypertensive pregnant patients mostly underwent surgery through caesarean section to deliver their babies accounting to 13 cases $(66 \%)$. About 19 patients or $34 \%$ only delivered normally.

\subsubsection{Maternal complication}

Around 54 reported cases (96\%) presented no complications. There were 2 cases (4\%) found with complications, which were identified as one case of post-partum haemorrhage and one case of hemolysis, elevated liver enzymes levels, and low platelet count (HELLP) syndrome.

\subsubsection{Maternal mortality}

The maternal outcome shows that $100 \%$ (56 cases) of the mothers were alive following delivery of their child. No maternal mortality noted during the period of 2008 to 2013. A more detailed description of maternal outcome is illustrated in Table 4:

Table 4: Maternal Outcome ( $\mathrm{N}=56)$

\begin{tabular}{ll}
\hline Demographic Characteristics & Frequency of Cases $(\%)$ \\
\hline Method of Delivery & $56(100)$ \\
Normal & $19(44)$ \\
Caesarian section & $37(66)$ \\
Maternal complication & $56(100)$ \\
None & $54(96)$ \\
With maternal complications* & $2(4)$ \\
Maternal mortality & $56(100)$ \\
Alive & $56(100)$ \\
Mortality & $0(0)$ \\
*Post-partum hemorrhage and hemolysis elevated liver enzymes levels, \\
and low platelet count (HELLP) syndrome
\end{tabular}

\subsection{Relationship between patients' profile and fetal out- come}

The findings show that $p$-values were more than the 0.05 levels indicate that there is no significant relationship between the patients' profiles across the fetal outcome. The results of relationship 
between patients' profile and fetal outcome are displayed in Table 5.

Table 5: Correlation Test between Patients' Profile and Fetal Outcome $(\mathrm{N}=56)$

\begin{tabular}{|c|c|c|c|c|c|}
\hline \multirow{2}{*}{$\begin{array}{l}\text { Profile } \\
\text { Variables }\end{array}$} & \multicolumn{5}{|c|}{ Fetal Outcome } \\
\hline & $\begin{array}{l}\text { Gestational } \\
\text { Age } \\
(p \text {-value })^{\mathrm{a}}\end{array}$ &  & 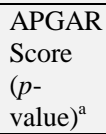 & $\begin{array}{l}\text { Birth } \\
\text { Defect } \\
(p- \\
\text { value })^{\mathrm{a}}\end{array}$ & $\begin{array}{l}\text { Fetal Dis- } \\
\text { position } \\
(p \text {-value })^{\mathrm{a}}\end{array}$ \\
\hline Age & 0.652 & 0.100 & 0.243 & 0.709 & 0.294 \\
\hline Gravidity & 0.134 & 0.390 & 0.861 & 0.322 & 0.282 \\
\hline Parity & 0.062 & 0.232 & 0.750 & 0.260 & 0.561 \\
\hline
\end{tabular}

${ }^{\mathrm{a}} p$-value, Sig. (2-tailed)

APGAR, test performed on babies at 1 and 5 minutes after birth.

\subsection{Relationship within and among fetal outcomes}

APGAR score $(p=0.001)$ and birth defect $(p=0.007)$ are positively and significantly related to fetal disposition. At the same time, APGAR and birth defect are also positively associated with each other $(p=0.003)$. Detailed descriptions of correlations within and among fetal outcomes are illustrated Table 6 .

Table 6: Correlation Test Within and Among Fetal Outcome $(\mathrm{N}=56)$

\begin{tabular}{|c|c|c|c|c|c|}
\hline $\begin{array}{l}\text { Fetal Out- } \\
\text { come }\end{array}$ & $\begin{array}{l}\text { Gestational } \\
\text { Age } \\
(p \text {-value })^{\mathrm{a}}\end{array}$ & $\begin{array}{l}\text { Fetal } \\
\text { Weight } \\
(p- \\
{\text { value })^{\mathrm{a}}}\end{array}$ & $\begin{array}{l}\text { APGAR } \\
\text { Score } \\
(p- \\
\text { value })^{\mathrm{a}}\end{array}$ & $\begin{array}{l}\text { Birth } \\
\text { Defect } \\
(p- \\
\text { value })^{\mathrm{a}}\end{array}$ & $\begin{array}{l}\text { Fetal Dis- } \\
\text { position } \\
(p \text {-value })^{\mathrm{a}}\end{array}$ \\
\hline $\begin{array}{l}\text { Gestational } \\
\text { Age }\end{array}$ & --- & 0.200 & 0.091 & 0.724 & 0.376 \\
\hline $\begin{array}{l}\text { Fetal } \\
\text { Weight }\end{array}$ & 0.20 & --- & 0.487 & 0.934 & 0.447 \\
\hline $\begin{array}{l}\text { APGAR } \\
\text { Score }\end{array}$ & 0.09 & 0.487 & --- & $\mathrm{0.003}^{*}$ & $0.001 *$ \\
\hline Birth Defect & 0.724 & 0.934 & $0.003 *$ & -- & $0.007 *$ \\
\hline $\begin{array}{l}\text { Fetal Dispo- } \\
\text { sition }\end{array}$ & 0.376 & 0.447 & $0.001 *$ & $0.007 *$ & --- \\
\hline
\end{tabular}

${ }^{a} p$-value, Sig. (2-tailed).

$*$ Significant at $<0.05$ level

Bold shows significant results.

APGAR, test performed on babies at 1 and 5 minutes after birth

\subsection{Relationship between patients' profile and maternal outcome}

Through the same tool of data analysis, patient's age and parity was found not to have any correlation and significant relationship with either method of delivery $(p=0.172,0.321)$ or maternal complication $(p=0.106,0.071)$. Likewise, gravidity is not correlated and not statistically significant with method of delivery ( $p=$ $0.172)$. However, gravidity $(r=0.266, p=0.048)$ showed that an increase in the gravidity would likely to have lesser complications on the mother. Table 7 shows the results of relationship between patients' profile and maternal outcome:

Table 7: Correlation Test between Patients' Profile and Maternal Outcome $(\mathrm{N}=56)$

\begin{tabular}{lll}
\hline Profile Variables & \multicolumn{2}{c}{ Maternal Outcome } \\
\cline { 2 - 3 } & $\begin{array}{l}\text { Method of Delivery } \\
(p \text {-value })^{\mathrm{a}}\end{array}$ & $\begin{array}{l}\text { Maternal Complication } \\
(p \text {-value })^{\mathrm{a}}\end{array}$ \\
\hline Age & 0.172 & 0.106 \\
Gravidity & 0.756 & $\mathbf{0 . 0 4 8} *$ \\
Parity & 0.321 & 0.071 \\
\hline${ }^{a} p$-value, Sig. (2-tailed). \\
*Significant at <0.05 level \\
Bold shows significant result.
\end{tabular}

\subsection{Relationship between fetal and maternal outcome}

Gestational age, fetal weight, APGAR score, birth defect and fetal disposition had no significant relationship with maternal complication $(p>0.05)$. In the same manner, these variables were not also correlated to method of delivery, except for fetal disposition, which shows a moderate and positive relationship $(p=0.000)$. This indicates that the more cesarean section was performed among the hypertensive mothers, the more the babies were admitted in NICU. Detail description of fetal and maternal outcome is shown in Table 8.

Table 8: Correlation Test between Fetal and Maternal Outcome (N=56)

\begin{tabular}{lll}
\hline Fetal Outcome & \multicolumn{1}{c}{ Maternal Outcome } \\
\cline { 2 - 3 } & $\begin{array}{l}\text { Method of Delivery } \\
(p \text {-value })^{\mathrm{a}}\end{array}$ & $\begin{array}{l}\text { Maternal Complica- } \\
\text { tion } \\
(p \text {-value })^{\mathrm{a}}\end{array}$ \\
\hline Gestational Age & 0.165 & 0.434 \\
Fetal Weight & 0.994 & 0.906 \\
APGAR Score & 0.950 & 0.750 \\
Birth Defect & 0.165 & 0.849 \\
Fetal Disposition & $\mathbf{0 . 0 0 0}^{*}$ & 0.455 \\
\hline
\end{tabular}

${ }^{a} p$-value, Sig. (2-tailed).

*Significant at $<0.05$ level

Bold shows significant result.

APGAR, test performed on babies at 1 and 5 minutes after birth

\section{Discussion}

Hypertension is considered the most common medical problem during pregnancies (Habli \& Siblai 2010). It was classified by the National High Blood Pressure Education Working Group (2000) as gestational or pregnancy induced, pre-eclampsia, eclampsia, chronic hypertension and pre-eclampsia superimposed on chronic hypertension which differ from their onset, signs, symptoms and severity (Towle \& Adams 2008). This present study found that women with hypertension were adults in the middle age, which were more than two-thirds of the total population. Similarly in the study of Hussein et al. (1998), majority of participants who were diagnosed with hypertension associated with pregnancy were between 25 to 29 years old. Also, similar findings were drawn by Wolde et al. (2011) and Chaim et al. (2008), indicating more than one-half of their study population at ages of 25 to 34 years old diagnosed with hypertension disease of pregnancy. Although American Heart Association cited that less than 20 years old and over 40 years old are at risk for acquiring hypertension-related pregnancy, the in-between ages are childbearing ages so there could be higher incidence of possible hypertension associated with pregnancy. Continuous review of the records showed multigravidas and multiparas tend to be affected by hypertension more than the primigravidas and primiparas. In confirmation, in the same study of Hussein, et al. (2008) and Al-Ghamdi et al. (1999), they found that fewer cases of primiparas with hypertension were admitted.

In this study, there were fewer recorded preterm babies (27\%). Comparing it to Wolde et al. (2011) study, similar pattern was established resulting to a preterm delivery rate of $31.6 \%$. Even though, a larger percentage of term babies were documented, prematurity was still a common complication of hypertensive disorder associated with pregnancy. In a research conducted by Bangal, et al. (2011), a considerable number of prematurity was identified in babies of women with mild to severe pregnancyinduced hypertension and eclampsia. Years back, study of Brown and Buddle (1996) established that fetal outcomes differ according to the type of hypertension. For example, women with superimposed pre-eclampsia had earlier deliveries, with lower average birth weights babies and more SGA babies. Out of 56 babies, $59 \%$ had appropriate weight in relation to their age and $66 \%$ had good APGAR score which substantiates the results of Chaim et al. (2008) who had $68.1 \%$ AGA newborns and $99.2 \%$ newborns with good APGAR score after 5 minutes of life. On the other hand, among the alive newborns, all were seen to have absence of any birth defect or congenital anomaly. But in a review on the study of the researchers of Kaisser Foundation Institute in California (2011), it was detected that around 5.4\% of babies born to women with high blood pressure has birth defects such as congenital heart defects and defects of the brain or spinal cord. Although newborns 
were mostly admitted (71\%), few were considered well babies $(27 \%)$ in this study. Comparable to other study, there were also high prevalence of live births, however, NICU admissions were lower (Wolde et al. 2011).

The majority of the cases ended to cesarean section. While vaginal delivery is indicated for non-complicated pregnancies, patient with hypertension could be at risk of life threatening event once labor had set in or even before that, such as surge of blood pressure causing maternal distress and in this case, cesarean section should be performed to save the mother and the baby (Medindia.net 2013). Furthermore, the study population presented no maternal mortality and $96 \%$ cases of no maternal complications. However, postpartum hemorrhage and HELLP syndrome were observed complications. There were very few studies that had indicated postpartum hemorrhage or bleeding as a complication of hypertension in pregnancy. In this study, the hemorrhage case had arisen from a normal delivery. Meanwhile, HELLP syndrome is a complication of pre-eclampsia affecting the liver organ (Towle \& Adams, 2008). Pre-eclampsia, which is type of hypertension associated with pregnancy, occurs with elevation of blood pressure after 20 weeks of gestation and presence of protein in the urine (Ladewig et al. 2010). Several studies had also pointed HELLP syndrome as one of the most common complications of hypertension in pregnancy such as research works of Hussein et al. (1998) and Vigil et al. (2004). Nevertheless, the work Al-Ghamdi et al. (2011) found no case of HELLP syndrome among their participants.

Most fetal outcomes did not show any association except for APGAR score, birth defect and fetal disposition. Babies with higher APGAR score and no birth defects were likely to be roomed-in with their mother; while, babies with good APGAR score seemed to have no birth defects. Babies were usually admitted in NICU if hypertensive mothers had undergone cesarean section. In comparison and contrast with other findings, Brown and Buddle (1996) saw association between birth weight and age of gestation, while Fatimeh et al. (2010) found differences in neonatal APGAR, NICU admission and birth weight. Finally, Hussein et al. (1998) identified maternal age and number of pregnancy (gravidity) to influence fetal mortality which was not found in this study.

\section{Conclusion}

The following conclusions were drawn based on the findings of the study: (1) majority of the pregnant women affected by hypertension were middle adult aged, multigravidas and multiparas; (2) most newborn were term, AGA, had good APGAR score, no birth defects but mostly admitted in NICU; (3) maternal complications are very low at $4 \%$ with a case of post-partum hemorrhage and HELLP syndrome. However, cesarean section was commonly performed; (4) APGAR score and birth defect were associated with each other as they were also associated with fetal disposition; and (5) less maternal complications were observed from multigravidity but more NICU admissions resulted from cesarean section.

This study recommends the development of a well-designed program plan for pregnant women to address significant problems toward improving maternal health and prevent pregnancy-related complications. Also, all healthcare team members, particularly nurses, must undergo updated medical education and formal trainings and seminars regarding maternal and neonatal nursing interventions that are essential to enhance the care for mothers with HDP. Lastly, additional research to examine the association of morbidity and mortality and fetomaternal outcomes among hospitalized hypertensive gravida is needed and highly recommended.

\section{Conflict of interest statement}

The authors declared that there is no conflict of interests.

\section{Acknowledgment}

This study received no specific research grant from any funding institution or other sectors.

\section{Author contributions}

Conceived and designed the research: RA; performed data collection: RA, RE; contributed to data analysis and interpretation: RA, RE and JMG; manuscript preparation: RA, RE and JMG. All authors agreed on the final manuscript.

\section{References}

[1] Al-Ghamdi SMG, Al-Harbi AS, Khalil A, \& El-Yahyia AR (1999), Hypertensive disorders of pregnancy: prevalence, classification and adverse outcomes in Northwestern Saudi Arabia. Annals of Saudi Medicine, 19(6), 557-560.

[2] Bangal VB, Giri PA, \& Mahajan AS (2011), Maternal and foetal outcome in pregnancy-induced hypertension: A study from rural Tertiary care teaching hospital in India. International Journal of Biomedical Research, 2(12). DOI: 10.7439/ijbr.v2i12.204 http://dx.doi.org/10.7439/ijbr.v2i12.204.

[3] Brown MA \& Buddle ML (1996), Hypertension in pregnancy: Maternal and fetal outcomes according to laboratory and clinical features, The Medical Journal of Australia, 165(7), 360-365.

[4] Ceasarean Section: Types and Indication of C Section. Available at $<$ http://www.medindia.net/surgicalprocedures/caesarean-sectiontypes-and-indications.htm>

[5] Chaim SRP, de Olivia SMJV, \& Kimura AF (2008), Pregnancyinduced hypertension and the neonatal outcome. Acta Paulista de Enfermagem, 21. Available at <http://dx.doi.org/10.1590/S010321002008000100008>

[6] Dolea C \& AbouZahr C (2003), Global burden of hypertensive disorders of pregnancy in the year 2000. Global Burden of Disease 2000, $1-11$.

[7] Fatemeh T, Marziyeh G, Navereh G, \& Samira T (2010), Maternal and perinatal outcome in nulliparous women complicated with pregnancy hypertension. Journal of Pakistan Medical Association, 60(9), 707-710.

[8] Habli M, \& Siblai BM (2010), Hypertensive disorders of pregnancy. In Ladewig, PAW, London, ML, Davidson, MR, Contemporary Maternal-Newborn Nursing Care $\left(7^{\text {th }}\right.$ Ed.). New Jersey: Pearson Education, Inc.

[9] Hafez SK, Dorgham LS and Sayed SAM (2014), Profile of High Risk Pregnancy among Saudi Women in Taif - Kingdom of Saudi Araba. World Journal of Medical Sciences, 11(1), 90-97. DOI: 10.5829/idosi.wjms.2014.11.1.83319

[10]Hussein MM, Mooij JM, Roujouleh H (1998). Hypertension in pregnancy: Presentation, management and outcome - A Retrospective Analysis of 135 Cases. Saudi Journal of Kidney Diseases Transplantation, 9, 416-424.

[11]Ladewig PAW, London ML, \& Davidson MR (2010), Contemporary maternal-newborn nursing care, $\left(7^{\text {th }}\right.$ Ed.), New jersy: Pearson Education, Inc.

[12]LeDuc Media (2014), Health profile: Saudi Arabia. Available at <http://www.worldlifeexpectancy.com/country-health-profile/saudiarabia>

[13]Leeman L \& Fontaine P (2008), Hypertensive disorders of pregnancy. American Family Physician, 78(1), 93-100.

[14]London ML, Ladewig PW, Ball JW, \& Bindler RC (2003), Maternalnewborn and child nursing (Family Centered Care). New Jersey: Pearson Education, Inc.

[15]Naeem MA, Naeem MU \& Hanif A (2014), Pregnancy outcome: A comparative study of hypertensive and normotensive Pakistani population. The Professional Medical Journal, 21(2), 347-353.

[16]Olusanya BO \& Solanke OA (2012), perinatal outcomes associated with maternal hypertensive disorders of pregnancy in a developing country. Hypertension in Pregnancy, 31, 120-130. http://dx.doi.org/10.3109/10641955.2010.525280.

[17]Patel ML, Sachan R, Gangwar R, Sachan P, Natu SM (2013), Correlation of serum neutrophil gelatinase-associated lipocalin with acute kidney injury in hypertensive disorders of pregnancy. International Journal of Nephrology and Renovascular Disease, 6, 181-186. DOI: $10.2147 /$ IJNRD.S45523 http://dx.doi.org/10.2147/IJNRD.S45523. 
[18]The World Bank (2014), maternal mortality ratio (modeled estimate, per 100,000 live births): Saudi Arabia Estimates. Available at <http://data.worldbank.org/indicator/SH.STA.MMRT/countries>

[19] The World Bank (2014), Mortality rate, infant (per 1,000 live births): Saudi Arabia Estimates. Available at <http://data.worldbank.org/indicator/SP.DYN.IMRT.IN/countries>

[20]Towle M \& Adams ED (2008), Maternal-child nursing care. New Jersey: Pearson Education, Inc.

[21]Vigil DGP, Montufar RC, \& Smith A (2004), Pregnancy and severe chronic hypertension: maternal outcome. Hypertensive Pregnancy, 23(3), 285-293. http://dx.doi.org/10.1081/PRG-200030315.

[22]Wolde Z, Segni H, \& Woldie M (2011), Hypertensive disorders of pregnancy in Jimma University Specialized Hospital. Ethiopian Journal of Health Sciences, 21(3), 147-154.

[23] World Health Organization, The United Nations Children's Fund \& The United Nations Population Fund (2002) Maternal Mortality in 2000, Estimates. New York. 